\title{
Carpal tunnel syndrome: elastosonographic strain ratio and cross- sectional area evaluation for the diagnosis and disease severity.
}

\author{
Idil Gunes Tatar ${ }^{1}$, Aydin Kurt ${ }^{1}$, Nese Gungor Yavasoglu², Baki Hekimoglu ${ }^{1}$ \\ ${ }^{1}$ Department of Radiology, ${ }^{2}$ Department of Neurology, Diskapi Training and Research Hospital, Ankara, Turkey
}

\begin{abstract}
Aim: To evaluate the role of gray scale ultrasonography (US) and real time elastosonography (RTE) in carpal tunnel syndrome (CTS). Materials and methods: Both wrists of 18 healthy volunteers $(n=36)$ formed the control group (Group 1$)$ and 19 symptomatic outpatients of the neurology clinic constituted the patient group. According to nerve conduction study results, cases with mild CTS $(n=15)$ formed Group 2; cases with moderate to severe CTS $(n=20)$ formed Group 3. Cross sectional area (CSA) and strain ratio (SR) were measured at carpal tunnel inlet (CTI) and $4 \mathrm{~cm}$ proximal to the distal end of the radius (P). CSA and SR change score $\left(\mathrm{CSA}^{\mathrm{CTI}}-\mathrm{CSA}^{\mathrm{P}}\right.$; $\left.\mathrm{SR}^{\mathrm{CTI}}-\mathrm{SR}^{\mathrm{P}}\right)$, CSA and SR ratio score $\left(\mathrm{CSA}^{\mathrm{CTI}} / \mathrm{CSA}^{\mathrm{P}}\right.$; $\left.\mathrm{SR}^{\mathrm{CTI}} / \mathrm{SR}^{\mathrm{P}}\right)$ were calculated. Results: The median nerve was significantly stiffer in Group 2 compared to Group 1; also in Group 3 compared to Group 1 $(\mathrm{p}=0.000)$. For CSA ${ }^{\mathrm{CTI}}$, the difference was significant between Group 1 and Group 3 ( $\left.\mathrm{p}=0.000\right)$, also between Group 2 and Group 3 ( $\mathrm{p}=0.001$ ). For CSA change scores the difference was only significant between Group 1 and Group $3(\mathrm{p}=0.015)$. In the diagnosis of CTS the best cut-off value for CSA ${ }^{\mathrm{CTI}}$ was $10.8(\mathrm{p}=0.001), 2.3$ for $\mathrm{SR}^{\mathrm{CTI}}(\mathrm{p}=0.000), 4.9$ for the CSA change score $(p=0.005), 0.05$ for the SR change score $(p=0.000), 1.3$ for the the CSA ratio score $(p=0.015)$ and 1.1 for the SR ratio score $(p=0.000)$. Conclusion: SR measurements do not exclude patients even with mild CTS but cannot categorize disease severity. CSA measurements on the other hand can categorize disease severity. Therefore, the combined use of US and RTE is suggested.
\end{abstract}

Keywords: median nerve, carpal tunnel syndrome, cross sectional area, elastosonography, strain ratio

\section{Introduction}

Carpal tunnel syndrome (CTS), first described by Phalen in the 1950s, consists of the entrapment of the median nerve within the carpal tunnel and constitutes about $90 \%$ of all entrapment neuropathies [1]. It has a prevalence of $5.8 \%$ in women and $0.6 \%$ in men [2].

Median nerve conduction study (NCS) demonstrates the severity of the disease and the level of the entrapment $[3,4]$ with moderate sensitivity of $(49 \%-84 \%)$ and a very high specificity $(95 \%-99 \%)$. A decrease in the median nerve motor conduction velocity is a typical electro-

Received 11.12.2015 Accepted 25.02.2016

Med Ultrason

2016, Vol. 18, No 3, 305-311

Corresponding author: Idil Gunes Tatar, M.D., Assoc. Prof. 12 Irfan Bastug Street 06110, Diskapi-Altındag/ Ankara, Turkey Phone:+90 3125962616

E-mail: idil.gunes.tatar@gmail.com physiological finding in CTS. Although NCS is the gold standard test for the diagnosis of CTS, it has some limitations which are the inability to evaluate the anatomy of the median nerve and the surrounding structures as well as the discomfort of the study.

Ultrasonography (US) has been extensively utilized in the diagnosis of CTS with the benefits of displaying ganglion cysts, mass lesions, and tenosynovitis. The most commonly used US method is the measurement of the cross-sectional area (CSA) of the median nerve at various levels within the carpal tunnel mostly at inlet, mid tunnel, and at outlet [5-9]. To reduce the discrepancies in the CSA measurements, comparison of the CSA of the median nerve within the carpal tunnel to an unaffected site such as the forearm has been proposed and the swelling ratio has been suggested as a promising method [10-12].

Doppler US has been used to detect the increase in the intraneural blood flow of the median nerve in CTS. In 
a systematic review of seven studies published between 1985 and 2013, Doppler US was concluded to be a promising diagnostic tool with the need of further studies to be implemented into routine practice [13]. In a study involving 101 patients with CTS, an image processing program was designed which calculates the sum of pixels in the intraneural vascular area on power Doppler US scans of the median nerve. The sum of pixels was significantly higher in patients than in controls, proposing the application of color Doppler US in the diagnosis of the CTS and evaluating its severity [14].

Real time elastosonography (RTE) has recently emerged as a sonographic method which measures the stiffness of the lesions and various tissues[15-20]. The utility of RTE in the CTS patients needs to be researched due to the limited number of studies in this field. The purpose of this study was to evaluate the utility of RTE in the diagnosis and the assessment of the severity of CTS and to determine the best cut-off values of the strain ratio (SR) measurements. We also analyzed the cut-off values of the cross sectional area (CSA) measurements of the median nerve determined by gray scale ultrasonography (US).

\section{Materials and methods}

\section{Study Sample}

After obtaining the approval of the institutional review board, 18 healthy volunteers who were working as hospital staff and 19 symptomatic outpatients of the neurology clinic were included in the study between April 2013 and May 2014. Informed consent was obtained from all participants. Clinical evaluation was carried out for all participants in the neurology department. Symptomatic patients were referred to NCS for the median nerve. Both wrists of healthy volunteers $(n=36)$ and symptomatic wrists of the patients whose NCS results were in accordance with CTS $(n=35)$ were examined in the radiology department.

Clinical diagnosis of CTS was based on the clinical diagnostic criteria of the American Academy of Neurology [3]: paresthesia and pain in the affected hand during night or in the morning, sensorial complaints which occur with repetitive hand movements, positive Phalen test, sensorial deficit, motor deficit, and atrophy in the area innervated by the median nerve. In the presence of at least one of these conditions patients underwent NCS of the median nerve. NCS was performed at room temperature with an electroneuromyography machine (Nicolet, Viking, EDX, USA). The electrophysiological findings obtained through the NCS were classified into four groups [21]: Normal: Electrophysiological findings within nor- mal range; Mild CTS: Sensory conduction abnormalities at the level of the wrist segment with preserved distal motor latency; Moderate CTS: Sensory conduction abnormalities at the level of the wrist segment and abnormalities of the distal motor response; Severe CTS: Absence of sensory response and abnormalities of the distal motor response

Exclusion criteria were represented by conditions which can cause CTS such as diabetes mellitus, thyroid disease, polyneuropathy, pregnancy, and previous surgery for CTS. We evaluated 71 wrists in 19 patients and 18 normal subjects, (29 women and 8 men), by US and RTE. The mean age of the patients was $46 \pm 13$ years (age range, 26-78 years) and the control group was $44 \pm 11$ years (age range, 22-75 years). The patient flow of the study is summarized in figure 1.

\section{Gray-scale US and RTE Evaluation}

All US examinations were carried out by a radiologist with 18 years of experience in sonography blinded to patient data. A second radiologist with 10 years of experience in sonography, who was also blinded to patient data, watched the whole examination and the images to be analysed were chosen in consensus. An ESAOTE Gold Platform MayLab 60, Genoa, Italy ultrasound machine with a linear probe of 4-13 MHz equipped with elastography software was used. During the examination, the patients were seated on the examination bed with the forearm lying on a box $25 \mathrm{~cm}$ high, the hand in supination position and fingers extended.

B-mode images were first obtained. Examination started with an overview of the volar side of the forearm to rule out any mass lesions and variations of the median nerve. The median nerve was examined in both longitudinal and transverse views. We chose to evaluate the median nerve at two levels: $4 \mathrm{~cm}$ proximal to the distal end of the radius (P) and at the carpal tunnel inlet (CTI). The CSA of the median nerve was determined in both places using a continuous boundary trace along the inner

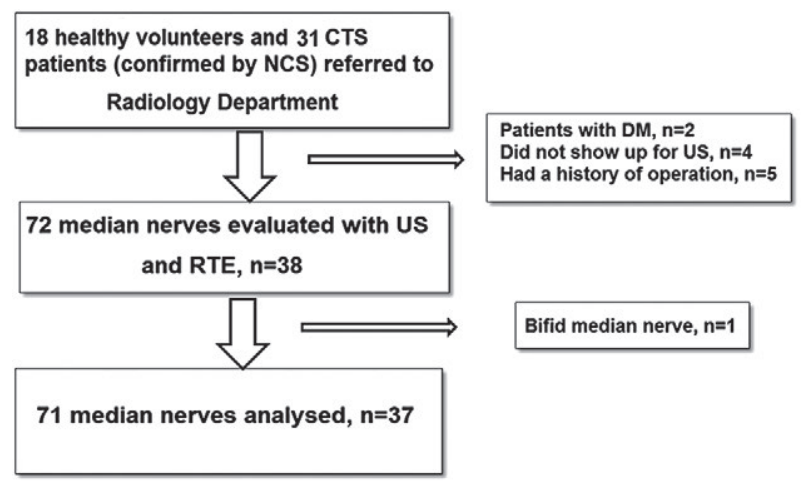

Fig 1. Flow diagram of patients included in the study 


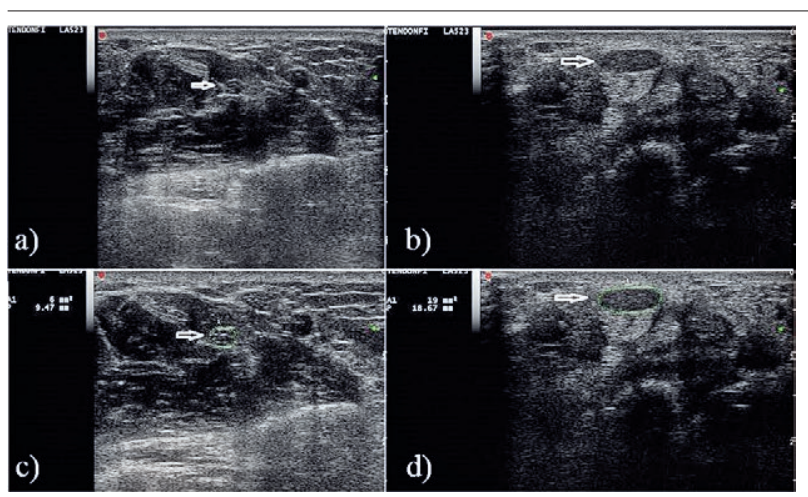

Fig 2. US examination of the median nerve (arrows) of a 37-year-old female patient with mild carpal tunnel syndrome at the proximal forearm, $4 \mathrm{~cm}$ proximal to the distal end of the radius (a) and at the level of carpal tunnel inlet, just before the proximal margin of the flexor retinaculum (b). The cross sectional area of the median nerve was $6 \mathrm{~mm}^{2}$ at the proximal forearm (c) and $19 \mathrm{~mm}^{2}$ at the level of carpal tunnel inlet (d).

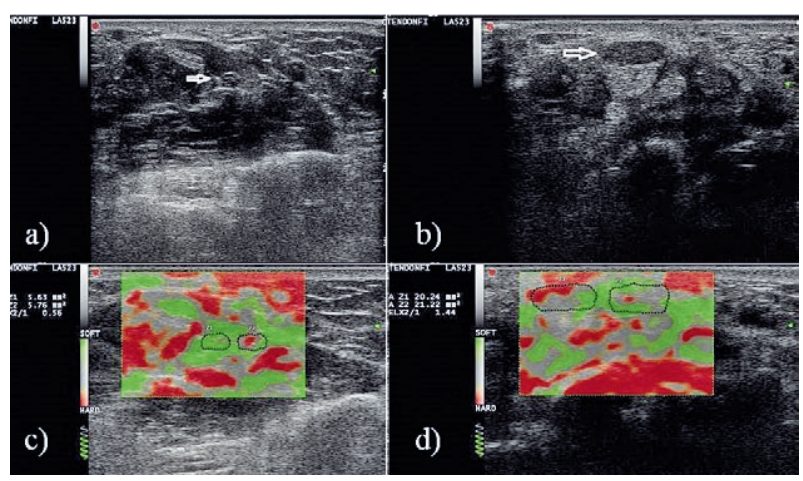

Fig 3. Elastosonographic examination of the median nerve (arrows) of the same 37-year-old female patient with mild carpal tunnel syndrome at the proximal forearm, $4 \mathrm{~cm}$ proximal to the distal end of the radius (a) and at the level of carpal tunnel inlet, just before the proximal margin of the flexor retinaculum (b). The strain ratio was 0.56 at the proximal forearm (c) and 1.44 at the level of carpal tunnel inlet (d). (Z1: strain of the median nerve, Z2: strain of the reference tissue).

hypoechoic border, excluding the surrounding echogenic rim. CSA calculations were automatically performed by the software (fig 2).

Afterwards RTE was performed by applying light vertical pressure followed by decompression until a good quality image was obtained. The software assisted the sonographer to be aware of the compression degree with the help of a spiral compression indicator in the right lower corner of the screen. The measurements were done when more than half of the spiral indicator was green. A color coded elastogram was displayed over the B-mode image ranging from green (soft) to red (hard). A regionof-interest (ROI) box was placed over the whole cross sectional area of the median nerve (average strain repre- sented as Z1) and the adjacent tissue at the same depth (average strain represented as Z2) was used as the reference. SR (Z2 / Z1) which reflects the stiffness of the median nerve was calculated. SR measurements were performed at both levels (fig 3).

All the B-mode and RTE measurements were conducted three times on the selected images and averaged to reduce the error. The US examinations were done on the same day of the NCS.

In each patient by taking the absolute difference between the gray scale CSA measurement at the level of carpal tunnel inlet $\left(\mathrm{CSA}^{\mathrm{CTI}}\right)$ and $4 \mathrm{~cm}$ proximal to the distal end of the radius $\left(\mathrm{CSA}^{\mathrm{P}}\right)$, CSA change score (CS$\mathrm{A}^{\mathrm{CTI}}-\mathrm{CSA}^{\mathrm{P}}$ ) was calculated. Division of the CSA ${ }^{\mathrm{CTI}}$ by the $\mathrm{CSA}^{\mathrm{P}}$ revealed the CSA ratio score $\left(\mathrm{CSA}^{\mathrm{CTI}} / \mathrm{CSA}^{\mathrm{P}}\right)$ for each patient. Similarly SR change score $\left(\mathrm{SR}^{\mathrm{CTI}}-\mathrm{SR}^{\mathrm{P}}\right)$ was calculated by determining the absolute difference between the strain ratio measurement at the level of carpal tunnel inlet $\left(\mathrm{SR}^{\mathrm{CTI}}\right)$ and strain ratio $4 \mathrm{~cm}$ proximal to the distal end of the radius $\left(\mathrm{SR}^{\mathrm{P}}\right)$, Division of the $\mathrm{SR}^{\mathrm{CTI}}$ by the $\mathrm{SR}^{\mathrm{P}}$ revealed the $\mathrm{SR}$ ratio score $\left(\mathrm{SR}^{\mathrm{CTI}} / \mathrm{SR}^{\mathrm{P}}\right)$ for each patient.

\section{Statistical Analysis}

The statistical analysis was performed using SPSS version 18.0 (SPSS Inc, Chicago, IL, USA). Receiveroperating-characteristics (ROC) curves for the ultrasonographic measurements of the median nerve were plotted to identify the best cut-off values for the diagnosis of CTS. Dunn's Z test, Kruskal-Wallis and Anova test were used for the analysis of CTS subgroups. The Tukey test was carried out to analyze whether there was a statistically significant differencebetween groups. $\mathrm{p}<0.05$ was considered to be statistical signficant.

\section{Results}

According to the NCS results 35 median nerves of 19 patients met the criteria for CTS. The gray scale and RTE measurements of the median nerve in healthy volunteers and the patients with CTS are summarized in Table I.

Fifteen median nerves were in accordance with mild CTS, 15 with moderate CTS, whereas only 5 demonstrated severe CTS. Due to the low number of cases with severe CTS, cases with moderate and severe CTS were included in the same group and the statistical analysis was performed for these three subgroups: Group 1, the control group ( $\mathrm{n}=36$ ); Group 2, wrists with mild CTS $(n=15)$ and Group 3, wrists with moderate to severe CTS $(n=20)$. The gray scale and RTE measurements of the median nerve of the CTS are detailed in Table II.

For the discrimination of CTS the best cut-off values of all the measurements are demonstrated in Table III. 
Table I. Mean cross sectional area and strain ratio measurements of the median nerve in control group and patients with carpal tunnel syndrome.

\begin{tabular}{lll}
\hline Control groupCTS group & & \\
\hline $\mathrm{CSA}^{\mathrm{CTI}}\left(\mathrm{mm}^{2}\right)$ & $10.51 \pm 3.10(5.00-18.17)$ & $13.89 \pm 5.37(8.00-34.00)$ \\
$\mathrm{CSA}^{\mathrm{P}}\left(\mathrm{mm}^{2}\right)$ & $7.37 \pm 2.32(4.00-12.3)$ & $7.68 \pm 2.51(5.00-14.54)$ \\
$\mathrm{CSA}^{2}$ change score & $3.14 \pm 2.56(-3.00-9.59)$ & $6.20 \pm 5.49(0.55-26.00)$ \\
CSA ratio score & $1.49 \pm 0.40(0.63-2.60)$ & $1.92 \pm .85(1.04-.67)$ \\
$\mathrm{SR}^{\mathrm{CTI}}$ & $1.85 \pm 0.65(1.00-3.72)$ & $3.08 \pm 1.00(1.14-4.84)$ \\
$\mathrm{SR}^{\mathrm{P}}$ & $2.83 \pm 1.03(1.02-4.99)$ & $2.11 \pm 0.75(1.27-4.79)$ \\
$\mathrm{SR}^{\text {change score }}$ & $-0.98 \pm 1.02(-3.28-1.15)$ & $0.97 \pm 1.04(-0.81-3.33)$ \\
SR ratio score & $0.73 \pm 0.35(0.25-2.13)$ & $1.57 \pm 0.64(0.60-3.22)$ \\
\hline
\end{tabular}

CTS: Carpal tunnel syndrome, CSA ${ }^{\mathrm{CTI}}$ : Cross sectional area of the median nerve at the level of carpal tunnel inlet, CSA $^{\mathrm{P}}$ : Cross sectional area of the median nerve at the proximal forearm, SR ${ }^{\mathrm{CTI}}$ : Strain ratio of the median nerve at the level of carpal tunnel inlet, $\mathrm{SR}^{\mathrm{P}}$ : Strain ratio of the median nerve at the proximal forearm.

Table II. Mean cross sectional area and strain ratio measurements of the median nerve in carpal tunnel syndrome subgroups.

\begin{tabular}{lll}
\hline & Mild CTSsubgroup & Moderate-Severe CTS subgroup \\
\hline CSA $^{\mathrm{CTI}}\left(\mathrm{mm}^{2}\right)$ & $10.91 \pm 1.79(8.00-14.00)$ & $16.12 \pm 6.08(9.00-34.00)$ \\
$\mathrm{CSA}^{\mathrm{P}}\left(\mathrm{mm}^{2}\right)$ & $6.26 \pm 0.88(5.00-7.00)$ & $8.75 \pm 2.82(6.00-14.54)$ \\
CSA change score & $4.65 \pm 1.93(3.00-8.00)$ & $7.37 \pm 6.92(0.5-26.00)$ \\
CSA ratio score & $1.77 \pm 0.39(1.43-2.60)$ & $2.03 \pm 1.07(1.04-4.67)$ \\
SR $^{\mathrm{CTI}}$ & $3.15 \pm .09(1.70-4.84)$ & $3.04 \pm 0.96(1.14-4.84)$ \\
SR $^{\mathrm{P}}$ & $2.03 \pm 0.75(1.27-4.03)$ & $2.18 \pm 0.77(1.40-4.79)$ \\
SR change score & $1.12 \pm 0.96(-0.0-3.06)$ & $0.86 \pm 1.11(-0.81-3.33)$ \\
SR ratio score & $1.64 \pm 0.64(1.00-3.13)$ & $1.57 \pm 0.64(0.60-3.22)$ \\
\hline
\end{tabular}

CTS: Carpal tunnel syndrome, CSA ${ }^{\text {CTI}}$ : Cross sectional area of the median nerve at the level of carpal tunnel inlet, CSA ${ }^{\mathrm{P}}$ : Cross sectional area of the median nerve at the proximal forearm, $\mathrm{SR}^{\mathrm{CTI}}$ : Strain ratio of the median nerve at the level of carpal tunnel inlet, $\mathrm{SR}^{\mathrm{P}}$ : Strain ratio of the median nerve at the proximal forearm.

Table III. Best cut-off values of median nerve measurements in patients with carpal tunnel syndrome.

\begin{tabular}{ll}
\hline Median Nerve Measurements & $\begin{array}{l}\text { Best Cut-off Values } \\
\text { (p values) }\end{array}$ \\
\hline CSA $^{\mathrm{CTI}}\left(\mathrm{mm}^{2}\right)$ & $10.8(\mathrm{p}=0.001)$ \\
CSA change score & $4.9(\mathrm{p}=0.005)$ \\
CSA ratio score & $1.3(\mathrm{p}=0.015)$ \\
SR $\mathrm{CTI}$ & $2.3(\mathrm{p}=0.000)$ \\
SR change score & $0.05(\mathrm{p}=0.000)$ \\
SR ratio score & $1.1(\mathrm{p}=0.000)$ \\
\hline
\end{tabular}

CTS: Carpal tunnel syndrome, CSA ${ }^{\text {CTI}}$ : Cross sectional area of the median nerve at the level of carpal tunnel inlet, SR ${ }^{\mathrm{CTI}}$ : Strain ratio of the median nerve at the level of carpal tunnel inlet.

\section{RTE Measurements}

$S R$ measurements at the level of carpal tunnel inlet: There was a statistically significant difference among the subgroups ( $p=0.000$ ). According to SR measurements the median nerve was significantly stiffer in Group 2 compared to Group 1; also in Group 3 compared to Group $1(\mathrm{p}=0.000)$. But there was not a statistically significant difference between Group 2 and Group $3(\mathrm{p}=0.922)$.

SR change score: There was a statistically significant difference among the subgroups $(\mathrm{p}=0.000)$. The differ- ence was significant between Group 1 and Group 2; also between Group 1 and Group $3(\mathrm{p}=0.000)$. But there was not a statistically significant difference between Group 2 and Group $3(\mathrm{p}=0.735)$.

$S R$ ratio score: There was a statistically significant difference among the subgroups $(\mathrm{p}=0.000)$. The difference was significant between Group 1 and Group 2; also between Group 1 and Group 3 ( $p=0.000$ ). But there was not a statistically significant difference between Group 2 and Group 3 ( $\mathrm{p}=0.735)$.

\section{Gray-Scale Measurements}

CSA measurements at the level of carpal tunnel inlet: There was a statistically significant difference among the subgroups $(\mathrm{p}=0.000)$. The difference was statistically significant between Group 1 and Group $3(\mathrm{p}=0.000)$, also between Group 2 and Group 3 ( $\mathrm{p}=0.001$ ). But there was not a statistically significant difference between Group 1 and Group $2(\mathrm{p}=0.945)$.

CSA change scores: There was a statistically significant difference among the subgroups $(\mathrm{p}=0.013)$. The difference was only statistically significant between Group 1 and Group 3 ( $\mathrm{p}=0.015)$. On the other hand there was not a statistically significant difference between Group 1 and Group $2(\mathrm{p}=0.245)$, similarly between Group 2 and Group $3(\mathrm{p}=1)$. 
CSA ratio scores: There was not a statistically significant difference among the subgroups $(\mathrm{p}=0.05)$.

\section{Discussions}

In this research none of the CSA measurement methods can discriminate patients with mild CTS from the control group. On the other hand all of the SR measurement methods in our study can discriminate both patients with mild CTS and patients with moderate to severe CTS from the control group. Nevertheless the inadequacy of the SR measurement by RTE is that it cannot determine the severity of the CTS which can be achieved by the measurement of the CSA at carpal tunnel inlet. All of the SR measurement methods used in this research demonstrated $p$ value of 0.000 which can suggest that RTE could be more sensitive compared to gray scale US in the diagnosis of CTS.

An exception is that in one patient with mild CTS and in another patient with severe CTS the SR ${ }^{\mathrm{CTI}}$ measurements obtained by RTE were even lower than the $\mathrm{SR}^{\mathrm{P}}$. Both of these patients had obviously increased CSA ${ }^{\mathrm{CTI}}$ compared to $\mathrm{CSA}^{\mathrm{P}}$. The inability of RTE to discriminate CTS in those two patients can be attributed to the decreased sensitivity of RTE in the cases with significant edema where the median nerve appeared completely hypoechoic without the differentiation of the inner hyperechoic nerve fibers. It should be kept in mind that severe edema of the median nerve can lead to decreased stiffness which can be misleading in the interpretation of SR results. In both patients there was a fourfold increase in the ratio of $\mathrm{CSA}^{\mathrm{CT}}$ to $\mathrm{CSA}^{\mathrm{P}}$. In such instances with extremely increased CSA ratio, we do not suggest the assesment of CTS only by RTE but the combined use of CSA and SR measurements.

The literature on elastographic SR analysis for the assessment of CTS is limited. Orman et al have published that mean tissue strain was lower in the patients with CTS than in the controls similar to our results [22]. Miyamoto et al concluded that elastography provided significant improvement in the diagnostic accuracy of the ultrasonographic assessment of CTS[23]. Ghajarzadeh et al analyzed 60 median nerves by using the blue and red pixels and their indexes in a three-dimensional matrix. Mean CSA, total blue pixels, and blue indexes were significantly different between cases with different degrees of severity and the controls. They concluded that sonoelastography could be used in the diagnosis and evaluation of the severity of CTS cases [24]. Kantarci et al have published a study utilizing quantitative shear wave elastography in which they concluded that median nerve stiffness was significantly increased in patients with carpal tunnel syndrome compared to healthy volunteers in accordance with the results of our study [25]. Furthermore the authors were also able to obtain higher median nerve stiffness values in patients with severe or extremely severe CTS compared to patients with mildly or moderately severe CTS unlike our results. This difference could be attributed to the difference of the elastographic technique, and the difference in the formation of the subgroups. Shear wave elastography could be more reproducible and accurate in the categorization of the severity of CTS when the two elastographic methods are compared.

The use of gray scale US for the evaluation of CTS has been widely studied. The measurement of CSA of median nerve is the most frequently used method for diagnosis of CTS by gray scale US. Two methods to analyze the swelling of the median nerve have been suggested. Swelling ratio, calculated as the ratio between the CSA at the distal radius and pisiform levels, has been reported to have very low sensitivity $(6 \%)$, revealing that internal comparison within the wrist is not a valid method [26]. On the other hand measurement of the swelling as the ratio of the CSA between the forearm and wrist at the level of pisiform has decreased the rate of false-negative results from $37 \%$ to $2 \%$ [27]. An alternative measurement of swelling calculated as the absolute change in the cross-sectional area between the forearm and carpal tunnel region has also shown high diagnostic accuracy at $96 \%$ to $100 \%$ sensitivity [28]. In a recent study with 643 wrists diagnosed as mild, moderate and severe CTS, Klauser et al calculated the difference and ratio of the CSA measurements of the median nerve at the carpal tunnel and the pronator quadratus muscle sites. Both parameters were succesful in detecting the severity of CTS [29].

Nevertheless the demonstrated cut-off values of the CSA measurements of the median nerve range between 9-12 $\mathrm{mm}^{2}$ with sensitivities between $73.4-99 \%$ and specificities between $57.1-100 \%$ among different studies [9,30-34]. These inconsistencies could be related to the measurement of the CSA of the median nerve at different levels as well as the selection of the study sample, since age, gender, and ethnic group may affect the thickness of the median nerve.

In this study the best cut-off value for CSA for the discrimination of CTS was $10.8 \mathrm{~mm}^{2}$ at the level of carpal tunnel inlet which was close to the results of the study conducted by Sarria et al [30]. They observed a meaningful swelling in the median nerve at the proximal, middle, and distal segments in CTS patients. For CSA greater than $11 \mathrm{~mm}^{2}$, the sensitivity, specificity, positive predictive value, and the negative predictive value were $73.4 \%$, 
$57.1 \%, 72.3 \%$ and $58.5 \%$, respectively, in the proximal and middle segments; $75 \%, 57.1 \%, 72.7 \%$ and $60 \%$ in the distal segments.

For the discrimination of CTS the best cut-off value for CSA change score was calculated as 4.9 which was higher than the study conducted by Klauser et al [29]. Klauser et al compared the CSA measurement of the median nerve acquired at the level of the carpal tunnel and more proximally at the level of the pronator quadratus muscle and calculated their differences. They declared that the use of the CSA difference with a threshold of 2 $\mathrm{mm}^{2}$ revealed the highest sensitivity and specificity $(99 \%$ and $100 \%$ respectively) in the diagnosis of CTS.

\section{Limitations of the study}

In this study 15 wrists were diagnosed with mild CTS, 15 wrists demonstrated moderate CT, whereas only 5 wrists revealed severe CTS. The mean CSA would have increased if the number of cases with severe CTS had been higher. CSA of the median nerve has been reported to increase with the severity of entrapment [35-37]. With the evaluation of a larger study sample the best cut-off points calculated in this study can be tested among the CTS subgroups to evaluate their contribution to categorization of the severity of the patients.

The inability of CSA measurements to discriminate patients with mild CTS from the control group can also be due to the low number of cases with mild CTS in our study. It should also be emphasized that not all of the studies in the literature using sonoelastography were able to discriminate both patients with mild CTS and patients with moderate to severe CTS from the control group. This discordance of the results could be attributed to the different elastosonographic methods used, which are more user dependent than others, or could be related to the differences in the selection of the patient group.

The small number of men in both the CTS and control groups may have also been a limitation, because gender was shown to affect nerve thickness [38]. Finally due to the high specificity values of NCS, false positivity was not expected in patients with positive CTS results who were included in our CTS group. Yet it has been reported that $13-27 \%$ of patients with CTS can have normal NCS results [39-41]. Therefore false negativity might have been an issue and some of the patients included in our control group might have had CTS.

\section{Conclusions}

According to this study RTE is very sensitive in the differentiation of CTS patients with both mild and moderate to severe disease from the control group. SR measurement by RTE can be strongly suggested since it does not exclude patients even with mild disease. Nevertheless RTE can not categorize the severity of the disease. The severity on the other hand can be achieved by the measurement of the CSA of the median nerve at the level of the carpal tunnel inlet by gray scale US. The combination of gray scale US and RTE can be recommended as well as the combination of symptoms, signs, diagnostic tests in the evaluation of every CTS suspected patient.

\section{Conflicts of interests: none}

\section{References}

1. Phalen GS. The carpal-tunnel syndrome. Seventeen years' experience in diagnosis and treatment of six hundred fiftyfour hands. J Bone Joint Surg Am1966; 48: 211-228.

2. de Krom MC, Knipschild PG, Kester AD, Thijs CT, Boekkooi PF, Spaans F. Carpal tunnel syndrome: prevalance in general population. J Clin Epidemiol1992; 45: 373-376.

3. Practice parameter for carpal tunnel syndrome (summary statement). Report of the Quality Standards Subcommittee of the American Academy of Neurology. Neurology1993; 43: 2406-2409.

4. Jablecki CK, Andary MT, So YT, Wilkins DE, Williams FH. Literature review of the usefulness of nerve conduction studies and electromyography for the evaluation of patients with carpal tunnel syndrome. AAEM Quality Assurance Committee. Muscle Nerve 1993; 16: 1392-1414.

5. Duncan I, Sullivan P, Lomas F. Sonography in the diagnosis of carpal tunnel syndrome. AJR Am J Roentgenol 1999; 173: 681-684.

6. Swen WA, Jacobs JW, Bussemaker FE, de Waard JW, Bijlsma JW. Carpal tunnel sonography by the rheumatologist versus nerve conduction study by the neurologist. J Rheumatol 2001; 28: 62-69.

7. Leonard L, Rangan A, Doyle G, Taylor G. Carpal tunnel syndrome- is high-frequency ultrasound a useful diagnostic tool? J Hand Surg Br 2003; 28: 77-79.

8. Yesildag A, Kutluhan S, Sengul N, et al. The role of ultrasonographic measurements of the median nerve in the diagnosis of carpal tunnel syndrome. Clin Radiol 2004; 59: 910-915.

9. Mallouhi A, Pülzl P, Trieb T, Piza H, Bodner G. Predictors of carpal tunnel syndrome: accuracy of gray-scale and color Doppler sonography. AJR Am J Roentgenol 2006; 186: 1240-1245.

10. Hobson-Webb LD, Massey JM, Juel VC, Sanders DB. The ultrasonographic wrist-to-forearm median nerve area ratio in carpal tunnel syndrome. Clin Neurophysiol 2008; 119: 1353-1357.

11. Keberle M, Jenett M, Kenn W, et al. Technical advances in ultrasound and MR imaging of the carpal tunnel syndrome. Eur Radiol 2000; 10: 1043-1050.

12. Visser LH, Smidt MH, Lee ML. Diagnostic value of wrist median nerve cross-sectional area versus wrist-to-forearm 
ratio in carpal tunnel syndrome. Clin Neurophysiol 2008; 119: 2898-2899.

13. Vanderschueren GA, Meys VE, Beekman R. Doppler sonography for the diagnosis of carpal tunnel syndrome: a critical review. Muscle Nerve 2014; 50: 159-163.

14. Ghasemi-Esfe AR, Khalilzadeh O, Vaziri-Bozorg SM, et al. Color and power Doppler US for diagnosing carpal tunnel syndrome and determining its severity: a quantitative image processing method. Radiology 2011; 261: 499-506.

15. Tatar IG, Teber MA, Ogur T, Kurt A, Hekimoglu B. Real time sonoelastographic evaluation of renal allografts in correlation with clinical prognostic parameters: comparison of linear and convex transducers according to segmental anatomy. Med Ultrason 2014; 16: 229-235.

16. Kurt A, Gunes Tatar I, Ipek A, Hekimoglu B. B-Mode and elastosonographic evaluation to determine the reference elastosonography values for cervical lymph nodes. ISRN Radiology 2013; 2013: 895287.

17. Tatar IG, Kurt A, Hekimoglu B. Ultrasound Elastography: A new era for vulnerable carotid plaque imaging? JournalCVS 2013; 1: 20-24.

18. Tatar IG, Kurt A, Yilmaz KB, Akinci M, Kulacoglu H, Hekimoglu B. The learning curve of real time elastosonography: a preliminary study conducted for the assessment of malignancy risk in thyroid nodules. Med Ultrason 2013; 15: 278-284.

19. Tatar IG, Kurt A, Yilmaz KB, Dogan M, Hekimoglu B, Hucumenoglu S. The role of elastosonography, gray-scale and colour flow Doppler sonography in prediction of malignancy in thyroid nodules. Radiol Oncol 2014; 48: 348-353.

20. Gunes Tatar I, Altunoglu H, Kurt A, et al. The role of salivary gland elastosonography in Sjögren's syndrome: preliminary results. Int J Rheum Dis 2014; 17: 904-909.

21. Padua L, Lo Monaco M, Padua R, Gregori B, Tonali P. Neurophysiological classification of carpal tunnel syndrome: assessment of 600 symptomatic hands. Ital Neurol Sci 1997; 18: 145-150.

22. Orman G, Ozben S, Huseyinoglu N, Duymus M, Orman KG. Ultrasound elastographic evaluation in the diagnosis of carpal tunnel syndrome: initial findings. Ultrasound Med Biol 2013; 39: 1184-1189.

23. Miyamoto H, Halpern EJ, Kastlunger M, et al. Carpal tunnel syndrome: diagnosis by means of median nerve elasticity--improved diagnostic accuracy of US with sonoelastography. Radiology 2014; 270: 481-486.

24. Ghajarzadeh M, Dadgostar M, Sarraf P, Emami-Razavi SZ, Miri S, Malek M. Application of ultrasound elastography for determining carpal tunnel syndrome severity. Jpn J Radiol 2015; 33: 273-278.

25. Kantarci F, Ustabasioglu FE, Delil S, et al. Median nerve stiffness measurement by shear wave elastography: a potential sonographic method in the diagnosis of carpal tunnel syndrome. Eur Radiol 2014; 24: 434-440.

26. Saracgil SN, Karatas M, Yerli H, Isiklar I, Karadeli E. Diagnostic significance of ultrasonography in carpal tunnel syn- drome and comparison with electrodiagnostic tests. Turk J Phys Med Rehabil 2009; 55: 13-18.

27. Hobson-Webb LD, Padua L. Median nerve ultrasonography in carpal tunnel syndrome: findings from two laboratories. Muscle Nerve 2009; 40: 94-97.

28. Klauser AS, Halpern EJ, De Zordo T, et al. Carpal tunnel syndrome assessment with US: value of additional crosssectional area measurements of the median nerve in patients versus healthy volunteers. Radiology 2009; 250: 171-177.

29. Klauser AS, Abd Ellah MM, Halpern EJ, et al. Sonographic cross-sectional area measurement in carpal tunnel syndrome patients: can delta and ratio calculations predict severity compared to nerve conduction studies? Eur Radiol 2015; 25: 2419-2427.

30. Sarría L, Cabada T, Cozcolluela R, Martínez-Berganza T, García S. Carpal tunnel syndrome: usefulness of sonography. Eur Radiol 2000; 10: 1920-1925.

31. Wong SM, Griffith JF, Hui AC, Lo SK, Fu M, Wong KS. Carpal tunnel syndrome: diagnostic usefulness of ultrasonography. Radiology 2004; 232: 93-99.

32. Keles I, Karagulle Kendi AT, Aydin G, Zöğ SG, Orkun S. Diagnostic precision of ultrasonography in patients with carpal tunnel syndrome. Am J Phys Med Rehabil 2005; 84: 443-450.

33. Wiesler ER, Chloros GD, Cartwright MS, Smith BP, Rushing J, Walker FO. The use of diagnostic ultrasound in carpal tunnel syndrome. J Hand Surg Am 2006; 31: 726-732.

34. Roll SC, Evans KD, Li X, Freimer M, Sommerich CM. Screening for carpal tunnel syndromeusing sonography. J Ultrasound Med 2011; 30: 1657-1667.

35. Padua L, LoMonaco M, Gregori B, Valente EM, Padua R, Tonali P. Neurophysiological classification and sensitivity in 500 carpal tunnel syndrome hands. Acta Neurol Scand 1997; 96: 211-217.

36. Phalen GS. The diagnosis of carpal tunnel syndrome. Cleve Clin Q 1968; 35: 1-6.

37. Kotevoglu N, Gulbahce-Saglam S. Ultrasound imaging in the diagnosis of carpal tunnel syndrome and its relevance to clinical evaluation. Joint Bone Spine 2005; 72: 142-145.

38. Ulaşli AM, Duymuş M, Nacir B, Rana Erdem H, Koşar U. Reasons for using swelling ratio in sonographic diagnosis of carpal tunnel syndrome and a reliable method for its calculation. Muscle Nerve 2013; 47: 396-402.

39. Atroshi I, Gummesson C, Johnsson R, Ornstein E, Ranstam J, Rosen I. Prevalence of carpal tunnel syndrome in a general population. JAMA 1999; 282: 153-158.

40. Bingham RC, Rosecrance JC, Cook TM. Prevalence of abnormal median nerve conduction in applicants for industrial jobs. Am J Ind Med 1996; 30: 355-361.

41. Bodofsky EB, Wu KD, Campellone JV, Greenberg WM, Tomaio AC. A sensitive new median-ulnar technique for diagnosing mild Carpal Tunnel Syndrome. Electromyogr Clin Neurophysiol 2005; 45: 139-144. 